\title{
A ASSISTÊNCIA E O ESTADO DE BEM ESTAR SOCIAL NO BRASIL
}

\section{THE ASSISTANCE AND THE WELFARE STATE IN BRAZIL}

\author{
Ana Beatriz Borges Ramos Duarte*
}

\begin{abstract}
Resumo: As políticas de assistência enquanto políticas sociais estão associadas ao desenvolvimento do Estado do Bem Estar Social. Tradicionalmente, as associações religiosas desenvolveram, no Brasil, trabalhos sociais voluntários filantrópicos e sem fins lucrativos em parceria com o Estado, que até o século XX não havia oficializado ainda a Assistência como política pública. A Constituição de 1988 significou um marco para as políticas de Assistência, introduzindo uma reforma no sistema de seguridade social, caracterizado, sobretudo, pela descentralização políticoadministrativa das políticas públicas. Os maiores problemas relacionados à ineficiência das políticas de assistência no Brasil atualmente estão relacionados a dificuldades nos processos de descentralização da assistência e participação da sociedade civil nas decisões acerca das políticas públicas.
\end{abstract}

Palavras-chave: Assistência. Estado do Bem Estar Social. Políticas Públicas.

Abstract: The assistance policies as social policies are associated with the development of the Welfare State. Traditionally, religious associations have developed voluntary, philanthropic and nonprofit social work in Brazil in partnership with the State, which until the twentieth century had not yet officialized Assistance as public policy. The 1988 Constitution represented a milestone for assistance policies, introducing a reform of the social security system, characterized above all by the political and administrative decentralization of public policies. The main problems related to the inefficiency of assistance policies in Brazil currently are related to difficulties in the processes of decentralization of assistance and participation of civil society in the decisions about public policies.

Keywords: Assistance. State of Social Welfare. Public policy.

\footnotetext{
"Mestra em Ciências Sociais pela UFRRJ (2017). Graduada em Ciências Econômicas pela UFRRJ (2013). Pesquisa o trabalho voluntariado de Associações Religiosas com pessoas em situação de rua.
} 


\section{INTRODUÇÃO}

Tradicionalmente, as associações religiosas desenvolveram, no Brasil, trabalhos sociais voluntários filantrópicos e sem fins lucrativos. Esses trabalhos sociais foram realizados ao longo dos anos em parceria com o Estado, que até o século XX não havia oficializado ainda a Assistência como política pública.

A Constituição de 1988 foi um marco essencial para as políticas públicas no Brasil, tendo sido responsável por uma reforma no sistema de seguridade social, caracterizado sobretudo pela descentralização político-administrativa das políticas públicas, que se consolida em 1993, com a instituição da Lei Orgânica da Assistência Social - LOAS. Os principais pontos positivos alcançados pela reforma foram o reconhecimento da Assistência Social, da Saúde e da Previdência enquanto direitos, e a universalização e gratuidade do acesso aos serviços assistenciais. Ou seja, a assistência ganha outro status após a nova Constituição, o de política pública e direito. A partir de então, com a descentralização, a sociedade civil passa a ter maior participação nas decisões e implementações de políticas públicas principalmente através de suas Associações, Conselhos e Orçamentos Participativos (DUARTE, 2015).

\section{A INSTITUCIONALIZAÇÃO DA POLÍTICA DE ASSISTÊNCIA E O ESTADO DO BEM-ESTAR SOCIAL}

A institucionalização da Assistência enquanto política pública está relacionada ao desenvolvimento do Estado do Bem Estar Social, ou Welfare State (SILVA, 2015). Segundo Draibe (2007), o Estado do Bem Estar surge a partir de uma nova realidade, a saber, a instituição do capitalismo moderno, que traz consigo os desequilíbrios sociais provenientes das grandes migrações rural-urbanas. É justamente pela necessidade de novos meios de proteção social que surgem as políticas sociais típicas do Estado do Bem Estar.

Segundo Kerstenetzky (2011), de uma maneira geral, o Estado do Bem Estar Social pode ser considerado "componente de uma estratégia desenvolvimentista", compreendendo "um conjunto articulado de instituições e políticas que, assegurando direitos sociais universais, podem contribuir ativamente 
para a equidade e para a expansão de recursos necessária à efetivação dos direitos" (p. 2). Logo, vemos que com o Estado do Bem Estar introduz-se a questão da efetivação dos direitos através das políticas sociais, e que para essa efetivação há uma forte expectativa no papel da Economia (desenvolvimentoeconômico).

\section{O ESTADO DO BEM ESTAR SOCIAL}

O Estado do Bem Estar Social, também conhecido como Welfare State, seria,segundo Medeiros (2001, p. 6), "a mobilização em larga escala do aparelho de Estado em uma sociedade capitalista a fim de executar medidas orientadas diretamente ao bem-estar de sua população".

Segundo Kerstenetzky (2011) o Estado do Bem Estar Social é caracterizado principalmente por sua responsabilização frente ao provimento do bem-estar de seus indivíduos e grupos, a partir do reconhecimento de que a economia de mercado, por si só, não é capaz de fazê-lo. Ou seja, o Estado do Bem Estar pressupõe forte atuação e interferência do Estado com vistas ao bem-estar de uma população.

O Estado do Bem Estar Social surge primeiramente na Alemanha ao fim do século XIX, e, logo depois, em outros países da Europa Ocidental e da América do Norte. É um fenômeno diretamente relacionado ao capitalismo industrial, e marcado pela presença da seguridade social e da extensão da cidadania política, tendo se consolidado no período entre guerras. Segundo Kerstenetzky (2011, p. 8), "os EBES [Estados do Bem Estar Social] não conformam uma entidade monopolítica", de maneira que dele emergemtrês tipos de regime, de acordo com a variação de suas instituições e resultados, queseriam o liberal, o conservador, e o social democrata. Apesar disso, de acordo com Medeiros (2001), o Estado do Bem Estar Social pressupõe a existência de algumas características comuns que norteiam sua atuação política, independente do regime em que se insere.

A primeira delas seria a regulação da economia capitalista por meio de políticasmacroeconômicas de cunho Keynesiano. Sendo assim, as políticas sociais teriam o papel de a) incentivar a expansão da demanda agregada e b) liberar as reservas de capital privado para investimentos, através da responsabilização do 
Estado pelos custos referentes aos riscos do emprego industrial. Dessa forma o Estado do Bem Estar funcionaria justamente como um instrumento capaz de reagir anticiclicamente às flutuações da demanda, conforme as teorias Keynesianas ${ }^{1}$ (MEDEIROS, 2001).

A segunda característica do Estado do Bem Estar Social seria a regulação política da sociedade através da mediação do Estado no processo de barganha entre capitalistas e trabalhadores. Ou seja, o Estado passa a regular o poder tanto de industriais como de trabalhadores através do firmamento do "compromisso Keynesiano" (mediação de relações privadas por instituições públicas democráticas com objetivos macroeconômicos), que permite, dentre outras coisas, certo controle da economia por parte dos representantes dos trabalhadores, redistribuição de ganhos de produtividade e pleno emprego, etc. Garantindoo controle dos riscos das relações de trabalho, o Estado do Bem Estar Social permite que os trabalhadores aceitem a condição de assalariamento, em vez de optar por outras formas de subsistência (MEDEIROS, 2001).

E em terceiro e último lugar, o Estado do Bem Estar Social seria responsável por aspectos relacionados à cultura política e à organização da máquina pública. Nele, a Burocracia teria papel fundamental, uma vez que os burocratas tem interesse direto nesse tipo de administração pública. Primeiro porque são eles próprios beneficiários das políticas sociais e segundo, porque a administração do

\footnotetext{
${ }^{1}$ A teoria Keynesiana é conhecida por defender a intervenção estatal na economia com o objetivo de conduzi-la ao pleno emprego. John Maynard Keynes foi o fundador da macroeconomia e suas teorias estão presentes em três principais obras: "The Economic Consequences of Peace" (As Consequências Económicas da Paz), 1919; "A Treatise on Money" (Um Tratado sobre Moeda), 1930; "General theory of employment, interest and money" (A Teoria Geral do Emprego, do Juro e da Moeda), 1992. Keynesteve enorme influência na renovação das teorias clássicas e na reformulação da política de livre mercado. Segundo Contador (1977, p. 133): "Um dos grandes legados da Teoria geral de Keynes foi questionar a ideia clássica de que o pleno emprego seria um estado e uma tendência natural da economia. Para o pensamento clássico até então reinante, o desemprego seria uma condição meramente transitória, pois os salários reais ajustar-se-iam garantindo um retorno automático ao pleno emprego. Uma vez nesta situação a oferta agregada criaria a sua própria demanda, perpetuando o pleno emprego. Esta argumentação ficou conhecida na literatura como "lei de Say". Ou seja, a economia estaria sempre operando ao longo da sua curva de possibilidades de produção. Em franca oposição, a revolução keynesiana enfatizou a ideia de que a economia poderia operar no interior da sua fronteira de possibilidades - e lá permanecer indefinidamente (...) Se a economia está operando a um nível muito inferior ao pleno emprego isto significa que recursos e fatores não são escassos - pelo menos temporariamente - e um acréscimo na produção pode ocorrer a um custo de oportunidade nulo ou negligível, bastando para isto incentivar a demanda efetiva ao nível adequado."
} 
Estado do Bem Estar Social depende da consolidação burocrática da máquina pública para conseguir prestar os serviços das políticas sociais (MEDEIROS, 2001).

\section{O ESTADO DO BEM ESTAR SOCIAL E A INTEGRAÇÃO ECONÔMICO-SOCIAL}

Com base no que foi exposto até aqui, pode-se concluir que o Estado do Bem Estar Social só existe devido ao capitalismo, e que se baseia num combinado de políticas sociais e econômicas.

Segundo Draibe (2007), o Estado do Bem Estar pressupõe uma gestão baseada tanto em políticas sociais como econômicas, que trabalham de maneira interdependente. Por este motivo, as políticas sociais estão geralmente relacionadas a fins de desenvolvimento econômico, e as políticas econômicas, por sua vez, são geralmente apontadas como condição para alcançar o desenvolvimento social. Essa relação é completamente variável de acordo com o tipo de regime adotado por cada Estado do Bem Estar, sendo algumas vezes mais propensa às políticas econômicas, e outras vezes, mais propensa ao desenvolvimento social ou humano.

A autora observa que nas últimas décadas há uma forte tendência entre diversos autores - entre os quais cita Taylor-Gooby (1998; 2001), Giddens (1998), Vandenbroucke (2005) - de enfocar demasiadamente o crescimento econômico como principal motivador do desenvolvimento social (DRAIBE, 2007). Segundo esse enfoque o desenvolvimento social se daria mediante a inserção produtiva, e essa concepção, ao influenciar vários governos, sobretudo latino-americanos, tem feito florescer programas que visam a capacitação, o emprego produtivo e o auto emprego, como as linhas de crédito específicas para microempresários, por exemplo. No entanto, tal corrente redundaria em "desprezo às questões de justiça social, universalidade e igualdade, com o quê, em última instância, encobriria sob roupagens da pós-modernidade um real ataque ao Estado de Bem-Estar"(SABEL; ZEITLIN, 2003 apud DRAIBE, 2007, p. 6). Ou seja, esse enfoque levaria à desconsideração das desigualdades pré-existentes, e das diferenças de oportunidades e acesso à renda. 


\section{O ESTADO DO BEM ESTAR SOCIAL NO BRASIL}

O Estado do Bem Estar, anteriormente considerado um tipo de governo existente apenas em países europeus desenvolvidos, recentemente passa a ser reconhecido em países de desenvolvimento tardio, porém sob novos conceitos específicos desses novos contextos. Uma categoria que permite pensar e comparar diferentes tipos de Estado do Bem Estar ao longo dos anos e em diferentes contextos é justamente o enfoque dos regimes ${ }^{2}$ de Bem Estar (DRAIBE, 2007).

Segundo Medeiros (2001), no Brasil, o surgimento do Estado do Bem Estar Social não esteve relacionado ao controle econômico da superprodução assim como nos Estados da América do Norte e da Europa Ocidental. Primeiro porque a superprodução não era um problema decorrente da demanda interna, e sim das flutuações do mercado externo, e segundo, porque as políticas de expansão do consumo não atingiriam um grande contingente de trabalhadores, já que o público afetado por elas era bastante restrito.

A instituição, propriamente dita, do Estado do Bem Estar Social no Brasil vai se dar na década na década de 1930 com o governo Vargas, considerado populista e autoritarista, principalmente no que tange às repressões aos movimentos trabalhistas. Nesse período as políticas sociais consagraram-se a partir de seu caráter conservador, e assim perduraram, sem importantes mudanças, até da década de 1960. Inclusive, foi nesse período que as bases do sistema de seguridade social foram definidas, e isso inclui: a criação do Ministério do Trabalho; expedição de nova legislação trabalhista; regulamentação do trabalho feminino, de menores, da jornada de trabalho, férias, demissões, e acidentes de trabalho; criação da Justiça do Trabalho; regulamentação da organização sindical; criação do Ministério dos Negócios de Educação e Saúde Pública, estatização da Previdência Social; participação paritária da União nas contribuições previdenciárias (MEDEIROS, 2001).

\footnotetext{
${ }^{2}$ Esping-Andersen que formulou em 1990 a tipologia dos três regimes de Bem Estar observados nos países desenvolvidos: o liberal, o conservador e o social democrata. Eles ficaram conhecidos como regimes de Esping-Andersen. Kerstenetzky (2011) se propôs a identificar qual tipo de regime estaria vigorando no Brasil na contemporaneidade, considerando as especificidades e historicidades que aqui se colocam, e observou que há certa combinação entre os três regimes apontados por EspingAndersen.
} 
A partir de 1964, com o regime militar, há a consolidação do sistema de seguridade social. O Estado do Bem Estar Social deixa de ter a característica populista, para assumir o caráter compensatório e produtivista. Isso significava, respectivamente, diminuir as desigualdades sociais e contribuir para o crescimento econômico. As políticas sociais tornaram-se mais abrangentes e complexas, devido ao maior investimento de recursos provenientes, inclusive, da iniciativa privada, através da privatização da política social. Essa privatização, no entanto, acarretou em maior transferência de recursos a estratos de maior renda, priorizando seus interesses (MEDEIROS, 2001).

A Constituição de 1988 foi responsável por uma reforma no sistema de seguridade social, caracterizadosobretudo pela descentralização políticoadministrativa das políticas públicas, que se consolida em 1993, com a instituição da Lei Orgânica da Assistência Social - LOAS. Os principais pontos positivos alcançados pela reforma foram o reconhecimento da Assistência Social, da Saúde e da Previdência enquanto direitos, e auniversalização e gratuidade do acesso aos serviços assistenciais. Destacam-se a criação do Sistema Único de Saúde, a criação do seguro-desemprego, o estabelecimento de piso mínimo para os benefícios previdenciários, dentre outras ações.

Reis e Silveira (2012), citando a Constituição Federal (1988), dizem:

Conforme estabelecido no artigo 194 da Constituição de 1988, o atual Sistema de Seguridade Social brasileiro "compreende um conjunto integrado de ações de iniciativa do poder público e da sociedade destinadas a assegurar os direitos relativos à saúde, à previdência e à assistência social". Quanto à forma de financiamento deste sistema, o artigo 195 estabeleceu que "a seguridade social será financiada por toda a sociedade, de forma direta e indireta, nos termos da lei, mediante recursos provenientes dos orçamentos da União, dos Estados, do Distrito Federal e dos Municípios, e das seguintes contribuições sociais" (BRASIL, 1988 apud REIS; SILVEIRA, 2012, p. 7).

Ou seja, de acordo com a nova Constituição, Saúde, Previdência e Assistência são direitos que devem ser providos por iniciativa do Estado e da sociedade.

Segundo Yasbek (2005), a Constituição de 1988 sugere uma nova visão acerca da pobreza urbana, uma vez que são introduzidas medidas que ampliam o 
debate acerca dos direitos universais dos indivíduos e não apenas da assistência das necessidades do pobre como uma visão meramente filantrópica.

Para Telles (2001), a política de Seguridade Social de 1988 marca o início de uma série de iniciativas Estatais que visam contemplar o pobre não inserido no mercado de trabalho formal. Considera que o alcance inédito da proteção social aos informais foi um marco, uma vez que na década de 80 , o mercado informal abrangia um contingente muito significativo da população economicamente ativa, que não tinha relevância, pois se encontrava "à margem das regras formais da "cidadania regulada" construídas no estreito figurino corporativo da tradição getulista e que, (...) mantém operante o princípio excludentemontado nos anos 30" (p. 4).

Costa (2005) defende que a nova Constituição e a LOAS permitiram considerar, pela primeira vez, a pessoa em situação de rua enquanto alvo da atuação do Estado, através das políticas públicas. Mas apesar do novo patamar alcançado pelo Estado do Bem Estar Social Brasileiro com as reformas da nova Constituição, reconhece que:

Ainda assim, nos últimos anos, concretizaram-se poucas iniciativas públicas destinadas a essa população. Merecem destaque os municípios, com experiências criativas e inovadoras, porém restritas diante da crescente demanda. As áreas de Saúde e Segurança atuaram de maneira indireta, restando apenas à Assistência Social equipamentos urbanos e projetos sociais (COSTA, 2005, p.6).

O próximo ponto se propõe a discorrer um pouco mais detalhadamente sobre os obstáculos que ainda hoje se impõe ao Estado do Bem Estar Social Brasileiro, e, consequentemente, à implementação e execução plenas de suas políticas de assistência, impedindo a atuação mais eficiente no que tange ao combate à desigualdade, a pobreza urbana, às pessoas em situação de rua, e outros problemas sociais a esses relacionados.

\section{DINÂMICAS E DIFICULDADES DA IMPLEMENTAÇÃO DO ESTADO DO BEM ESTAR NO BRASIL}

Os maiores problemas relacionados à não eficiência das políticas de assistência no Brasil atualmente estão relacionados a dificuldades nos processos de 
descentralização da assistência e participação da sociedade civil nas decisões acerca das políticas públicas, previstos na Constituição Federal. Como dito anteriormente, a descentralização político-administrativa da assistência requer 1) maior responsabilidade dos Estados e Municípios no financiamento e execução de políticas públicas assistenciais e 2) a criação dos Conselhos Municipais de Assistência Social (abertura para a participação da sociedade civil).

Segundo Campos (2005), o funcionamento do Conselho Municipal de Assistência Social (CMAS) pressupõe a existência de uma vida civil organizada formada por sindicatos, partidos políticos organizados, entidades comunitárias, religiosas, etc.

Segundo Bulla e Leal (2004):

A representação da sociedade civil no CMAS vem sendo realizada por três segmentos: entidades e organizações de assistência social, profissionais da área social, e usuários da assistência social. Os assistentes sociais integram, junto com os psicólogos, o segmento dos profissionais da área (BULLA; LEAL, 2004, p. 8).

Ou seja, uma das formas de descentralização é justamente a formação do Conselho Municipal de Assistência Social, que é composto por assistentes sociais, psicólogos, usuários da assistência e entidades de assistência.

Há, porém, entre alguns dos autores já citados (COSTA, 2005; CAMPOS, 2005; BULLA; LEAL, 2004; FONTENELE, 2007), a concordância no fato de que a descentralização político-administrativa da Assistência Social não tem funcionado como deveria, de acordo com o que está previsto em Lei. Ou seja, há alguns fatores que impedem ou dificultam a atuação plena dos Municípios e da Sociedade Civil nas políticas de assistência.

A descentralização político-administrativa tem, no âmbito da União, as diretrizes, regras e ações que norteiam o ordenamento político e institucional da assistência. Sendo assim, umadas questões pertinentesao tema da descentralização é o fato de que os procedimentos assistenciais adotados nos Municípios seguem um plano nacional pré-estabelecido que não observa a especificidade das diversas regiões brasileiras.Além disso, considera-se também o problema da fragilidade dos movimentos sociais municipais - pouco expressivos politicamente, sobretudo nos municípios de menor porte - e da "cultura política centralizadora", que estaria 
relacionada às "benevolências" de políticos que mantêm práticas patrimonialistas de governo, simplesmente prestando favores à população em troca de reconhecimento, e tratando os direitos como benevolência; a assistência como assistencialismo (CAMPOS, 2005).

Fontenele (2007) relaciona ainda os seguintes problemas com respeito ao processo descentralizador da assistência:

Especificamente sobre a fragilidade do processo de descentralização da política de Assistência Social no Brasil, destacam-se alguns pontos: a inexistência de um projeto nacional de reforma da Assistência Social, no âmbito federal; as relações de patronagem entre a esfera federal e o poder local; a fragilidade política do movimento de apoio a esse projeto; o aparato institucional disforme, desarticulado e descontínuo, perpassado pelo clientelismo; as questões relativas à clientela, baixa vocalização, dificuldade de definição; a ausência de uma política nacional, enquanto um conjunto articulado de uma rede de serviços; depois o fato de que, essencialmente, não foram viabilizadas condições como autonomia dos entes federados, favorecimento da capacidade organizacional, efetivo financiamento das ações (LIMA, 2003; ALMEIDA, 1996). Yazbek ainda acrescenta os seguintes problemas, segundo Stein: "grande concentração de poder no executivo, nas três esferas de governo; existência de poder paralelo ao 'comando único', previsto na LOAS, com forte presença e poder da 'primeira-dama'; precariedade da rede de assistência, ausência de fluxos de comunicação de uma esfera de governo para a outra e entre os conselhos nacional, estaduais e municipais; dificuldades na compreensão sobre o que são mínimos sociais e o que são entidades assistenciais" (STEIN, 1999, p. 41). (FONTENELE, 2007, p. 154).

Logo, vemos que fatores como relações de patronagem, clientelismo, falta de uma rede nacional articulada de serviços, falta de autonomia e financiamento dos Municípios e Estados são grandes vilões do "fracasso" do projeto de descentralização da Assistência.

Bulla e Leal (2004) apontam os problemas existentes na formação do CMAS, no que diz respeito à representação da sociedade civil. Segundo as autoras, a instituição do CMAS faz parte de um contexto de democratização do Estado e maior representação da sociedade civil na implementação de políticas em diversas áreas (educação, saúde, previdência, etc), através da criação dos conselhos gestores de políticas públicas baseados na Constituição de 1988. Por outro lado, as 
autoras questionam se, de fato, a participação da sociedade civil nos CMAS tem sido democráticas. O que as autoras entendem por participação democrática nos Conselhos é colocado a seguir:

\begin{abstract}
Para que realmente esses espaços se fortaleçam como mecanismos de aperfeiçoamento da democracia e fortalecimento da cidadania, faz-se necessário que os representantes construam uma representação pautando sua intervenção na defesa de interesses coletivos e não de interesses particulares. $E$, para isso, é imprescindível que se contemple também a participação dos cidadãos nas decisões do conselho. A representação, entendida como a defesa de interesses gerais de determinados grupos por pessoas escolhidas para esse fim, pressupõe que, para representar determinado grupo ou segmento, o representante deve conhecer as demandas e necessidades desse segmento. Para que uma representação seja considerada democrática, ela deve ser desenvolvida de forma visível e transparente e com a participação dos grupos ou segmentos representados. (BULLA; LEAL, 2004, p. 5)
\end{abstract}

Ou seja, segundo essa visão, é imprescindível a escolha democrática dos cidadãos para a formação dos Conselhos, pois eles são os representantes da sociedade na tomada de decisões. Porém, em pesquisa realizada pelas autoras no CMAS de Santa Maria, RS, a constatação é clara:

Analisando as informações, conclui-se que não existem critérios definidos para a escolha dos representantes da sociedade civil. Os representantes não estão sendo escolhidos de forma democrática, a indicação é a forma predominante de escolha. A eleição é pouco utilizada e, quando ocorre, dá-se de forma isolada e não em fórum específico dos três segmentos que compõem a sociedade civil (BULLA; LEAL, 2004, p. 10).

Além do processo de escolha considerado "não democrático" dos representantes da sociedade civil nos CMAS, Bulla e Leal (2004), ainda constataram os seguintes problemas: 1) a maioria dos representantes faz parte também de outros Conselhos do Município, o que tira dos usuários das políticas assistenciais a possibilidade de representarem melhor seu segmento no CMAS; 2) a escolha dos representantes deveria ser feita por usuários da assistência social; 3) os representantes não demonstraram conhecimento sobre a legislação da política de assistência social e sobre as atribuições do conselheiro.

Logo, vemos que a não concretização plena da descentralização é um fator 
que impede a execução de políticas públicas mais eficientes que contemplem os cidadãos inseridos na realidade da pobreza urbana, dificultando a ação mais engajada dos Municípios e da Sociedade Civil na Assistência Social enquanto direito. Por isso julga-se necessário discorrer melhor no próximo ponto acerca da diferença entre assistência enquanto direito e assistencialismo.

\section{CONSIDERAÇõES FINAIS}

O presente texto permite ter uma visão geral de como as políticas de assistência se relacionam com o contexto prévio de implementação do Estadodo Bem Estar Social, o que contribuiu para a tendência de universalização dos direitos no mundo e no Brasil.

Vemos que o Estado do Bem Estar é uma tendência que tem alcançado diversos países de base capitalista, e que, por mais que possua características comuns a todos esses países - como políticas econômicas de cunho Keynesiano mantém particularidades que acompanham as especificidades de cada país.

No caso específico do Brasil, vemos que o Estado do Bem Estar Social origina-se de maneira distinta dos países desenvolvidos, como estratégia governamental para aconstituição da força de trabalho necessária à modernização e ao desenvolvimento, tendo funcionado durante alguns anos sob caráter repressivo, a fim de antecipar possíveis exigências da classe trabalhadora. $O$ caráter centralizado das políticas sociais perdurou até o fim da década de 1980, e contribuiu para impossibilitar a diminuição das desigualdades. A constituição federal de 1988 trouxe novidades significativas ao sistema de seguridade social que passou a se aproximar da universalização de direitos própria dos regimes sociais democratas, principalmente através da descentralização político-administrativa da política social.

Mesmo assim, vemos que existem fatores que impedem a plena implementação e execução das políticas sociais a nível estadual e municipal, incluindo a centralização do plano nacional de assistência, a precariedade na organização da sociedade civil, a formação pouco democrática dos Conselhos Municipais de Assistência Social, a relação de patronagem da esfera federal em relação aos Estados e Municípios e outros. 
Esses fatores fazem com que o Estado de Bem Estar Social não se consolide em termos de efetividade das políticas, e trazem um panorama de insuficiência das políticas sociais. Em decorrência disso, percebe-se a atuação da sociedade civil em atividades assistencialistas por vezes desvinculadas da ação estatal.

\section{REFERÊNCIAS}

BULLA, Leonia Capaverde; LEAL, Maria Laci Moura. A participação da sociedade civil no Conselho Municipal de Assistência Social: o desafio de uma representação democrática. Textos \& Contextos,Porto Alegre, v. 3, n. 1, 2004: 1-13.

CAMPOS, Edval Bernardino. A complexa descentralização da política de assistência social.In: JORNADA INTERNACIONAL DE POLÍTICAS PÚBLICAS,2., 2005, São Luís. Anais [...]. São Luís: UFMA,2005.

CONTADOR, Cláudio R. Crescimento econômico e o combate à inflação. Revista brasileira de economia, [S.I.], v. 31, n. 1, p. 131-168, 1977.

COSTA, Ana Paula Motta. População em situação de rua: contextualização e caracterização. Textos \& Contextos, Porto Alegre, v. 4, n. 1, p. 1-15, 2005.

DUARTE, Ana Beatriz Borges Ramos. Trabalho voluntário e assistência em igrejas protestantes no Brasil: um estudo de caso sobre o "Sopão" da Igreja Evangélica Congregacional de Mato Alto - RJ. 2017. Dissertação (Mestrado em Ciências Sociais) - Programa de Pós-Graduação em Ciências Sociais, Universidade Federal Rural do Rio de Janeiro, Seropédica, 2017.

DRAIBE, Sônia M. Estado de bem-estar, desenvolvimento econômico e cidadania: algumas lições da literatura contemporânea. In: Hochman G. (Org.). Políticas Públicas no Brasil. Rio de Janeiro: Editora Fiocruz; 2007. p. 27-64.

FONTENELE, lolanda Carvalho. A Política de Assistência Social no Brasil: O foco na família e a questão dos mínimos sociais. Sociedade em Debate, Pelotas, p. 153173, jul-dez/2007.

KERSTENETZKY, Celia Lessa. Políticas sociais sob a perspectiva do Estado do Bem-Estar Social: desafios e oportunidades para o "catching up" social brasileiro. Niterói: Faculdade de Economia, 2011. Texto para Discussão n. 34, mar. 2011.

MEDEIROS, Marcelo. A trajetória do Welfare State no Brasil: papel redistributivo das políticas sociais dos anos 1930 aos anos 1990. Brasília, DF: IPEA, 2001. Texto para discussão, n. 852.

REIS, P. R. C.; SILVEIRA, S. F. R. Estado de Bem-Estar e Seguridade Social: 88 
Anos de Políticas Previdenciárias no Brasil.In: ENCONTRO NACIONAL DE PESQUISADORES EM GESTÃO SOCIAL, 6., 2012, São Paulo Anais [...]. São Paulo: ENAPEGS, 2012.

SILVA, Maria Ozanira da et al. Origem e desenvolvimento do Welfare State. Revista de Políticas Públicas, [S.I.], v. 1, n. 1, p. 77-104, 2015.

TELLES, Vera Silva. A nova questão social brasileira: ou como as figuras do nosso atraso viraram símbolo de nossa modernidade.In: TELLES, Vera Silva. Pobreza e Cidadania, São Paulo, Editora 34, 2001. p. 139-166.

YAZBEK, Maria Carmelita. A pobreza e as formas históricas de seuenfrentamento. Revista de Políticas Públicas, [S.I.], v. 9, n. 1, 2005. 